\title{
Three-dimensional Power Doppler Ultrasonography for Discriminating Benign from Malignant Ovarian Tumors: Current Experience
}

\author{
Juan Luis Alcázar \\ Department of Obstetrics and Gynecology, Clínica Universitaria de Navarra, School of Medicine \\ University of Navarra, Pamplona 31008, Spain \\ Correspondence: Dr. Juan Luis Alcázar \\ Department of Obstetrics and Gynecology. Avenida Pio XII, 3631008 Pamplona, Spain \\ Tel: 34-948-255400, Fax: 34-948-296500, e-mail: jlalcazar@unav.es
}

\begin{abstract}
The differential diagnosis of adnexal masses still constitutes a major clinical challenge. B-mode ultrasonography is the most used imaging technique and it is the base for this differential diagnosis with acceptable results in terms of sensitivity but a relatively high false positive rate for predicting ovarian cancer. The role of pulsed Doppler remains controversial and seems to be not reproducible in clinical practice. In the last years, a new technology such as 3D ultrasound-both morphology and 3D Angio power Doppler-has become available for discriminating between benign and malignant ovarian tumors. In this article I aim to review critically recent literature of this topic.
\end{abstract}

Key words: Adnexal masses, Power Doppler ultrasound, and Threedimensional ultrasound.

\section{INTRODUCTION}

Differentiating benign from malignant adnexal masses represents one of the most challenging problems in gynecological practice. Accurate surgical staging and cytoreductive surgeries have been proved to be among the main prognostic factors in ovarian cancer. ${ }^{1}$ For this reason patients with questionable adnexal masses should be referred for primary surgery to specialized centers for gynecologic oncology with experienced surgeons and adequate resources. On the other hand, benign tumors should be treated by minimally invasive surgery, ${ }^{2}$ even expectant management may be an option.,4 Therefore, accurate diagnosis is essential in order to establish the optimal management for these patients.

Ultrasound is currently accepted as the primary imaging modality in ovarian tumors. Therefore, ultrasound has become the main triage method prior to treatment. The optimal ultrasound approach to characterize adnexal masses remains to be established. Most examiners base their presumptive diagnosis on the sonographic morphologic features of the adnexal mass. ${ }^{5}$ However, others use multiparameter-scoring systems. ${ }^{6-9}$ There are several sonographic features, such as the presence of thick wall, thick septations, papillary projections, solid nodules, and ascites associated with a higher probability of malignancy. Multivariate analyses have demonstrated that the most predictive features for malignancy are papillary projections and solid nodules. ${ }^{10}$

A recent review showed that pooled sensitivity for B-mode gray-scale ultrasound $\sim 90 \%$, either by subjective examiner impression or applying scoring systems, with a false-positive rate $\sim 25 \%$. ${ }^{11}$

Pulsed and color Doppler allow the assessment of tumor vascularization. Early studies using spectral pulsed Doppler indexes were encouraging. ${ }^{12,13}$ However, subsequent studies challenged these results, showing a great overlapping of pulsed Doppler indexes between benign and malignant tumors. ${ }^{14}$ Multivariate analyses showed that blood flow location within the tumor was the most predictive parameter for distinguishing benign from malignant ovarian tumors using color Doppler. ${ }^{15,16}$

In spite of these controversies, a meta-analysis showed that the addition of color Doppler to gray-scale ultrasound would increase the specificity of ultrasound from 75 to $90 \% .{ }^{17}$ The problem was how to integrate both examinations to yield reproducible and clinically relevant results.

In the last few years, 3D ultrasound-both morphology and 3D Angio power-Doppler have been proposed for improving our ability to discriminate between benign and malignant adnexal masses. In this review I aim to evaluate critically recent literature of this new technology. 


\section{STATIC THREE-DIMENSIONAL ULTRASOUND}

Three-dimensional ultrasonography (3D US) overcomes some limitations of conventional two-dimensional ultrasound (2D US) allowing a more detailed assessment of morphologic features of the object studied, with no restriction to the number and orientation of the scanning planes.
Obtaining images from all spatial planes and eliminating echoes by using the "threshold" function are among the advantages of this technique. The first allows a more detailed assessment of intracystic structures (Figs 1 and 2) and the second allows eliminating internal echoes mimicking solid tissue, such as clots, debris and fatty and mucinous plugs (Table 1).

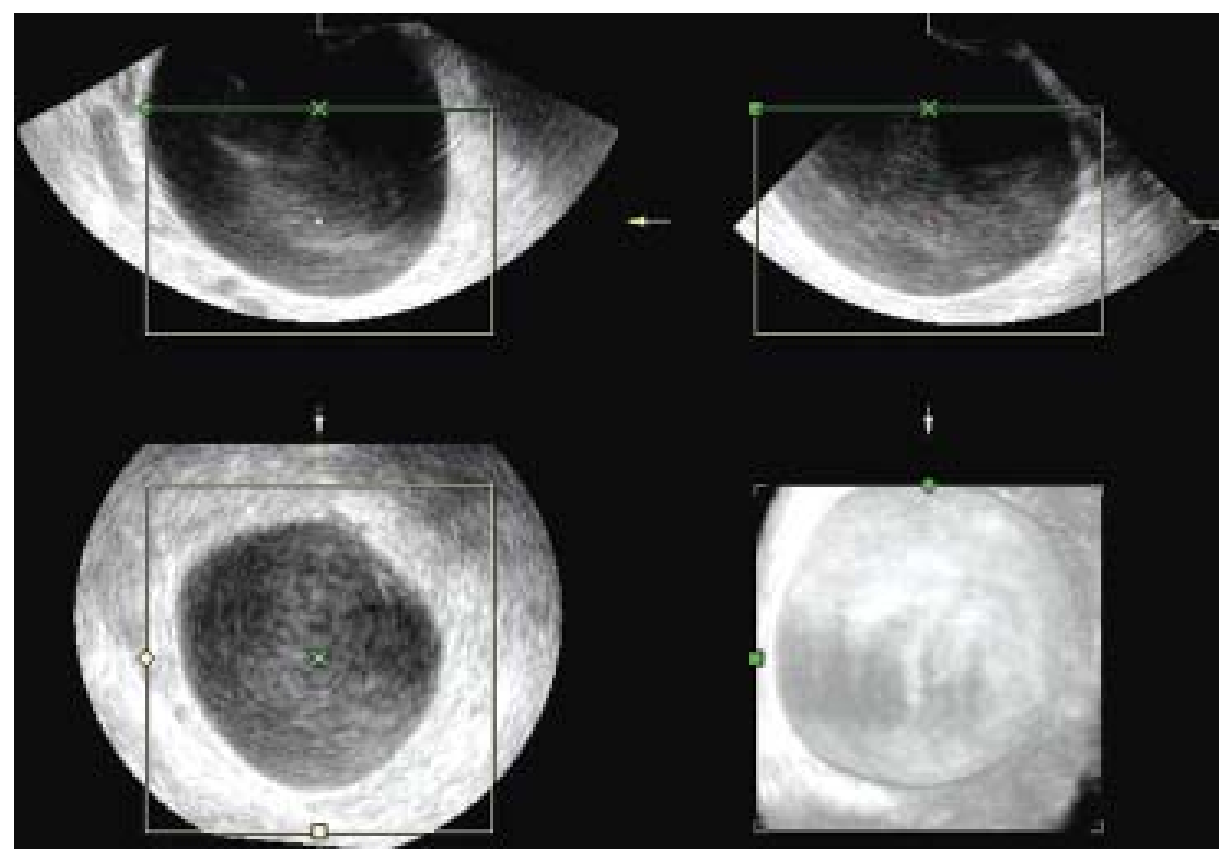

Fig. 1: Three-dimensional surface rendering from the internal wall of a simple ovarian cyst. A smooth surface is clearly seen

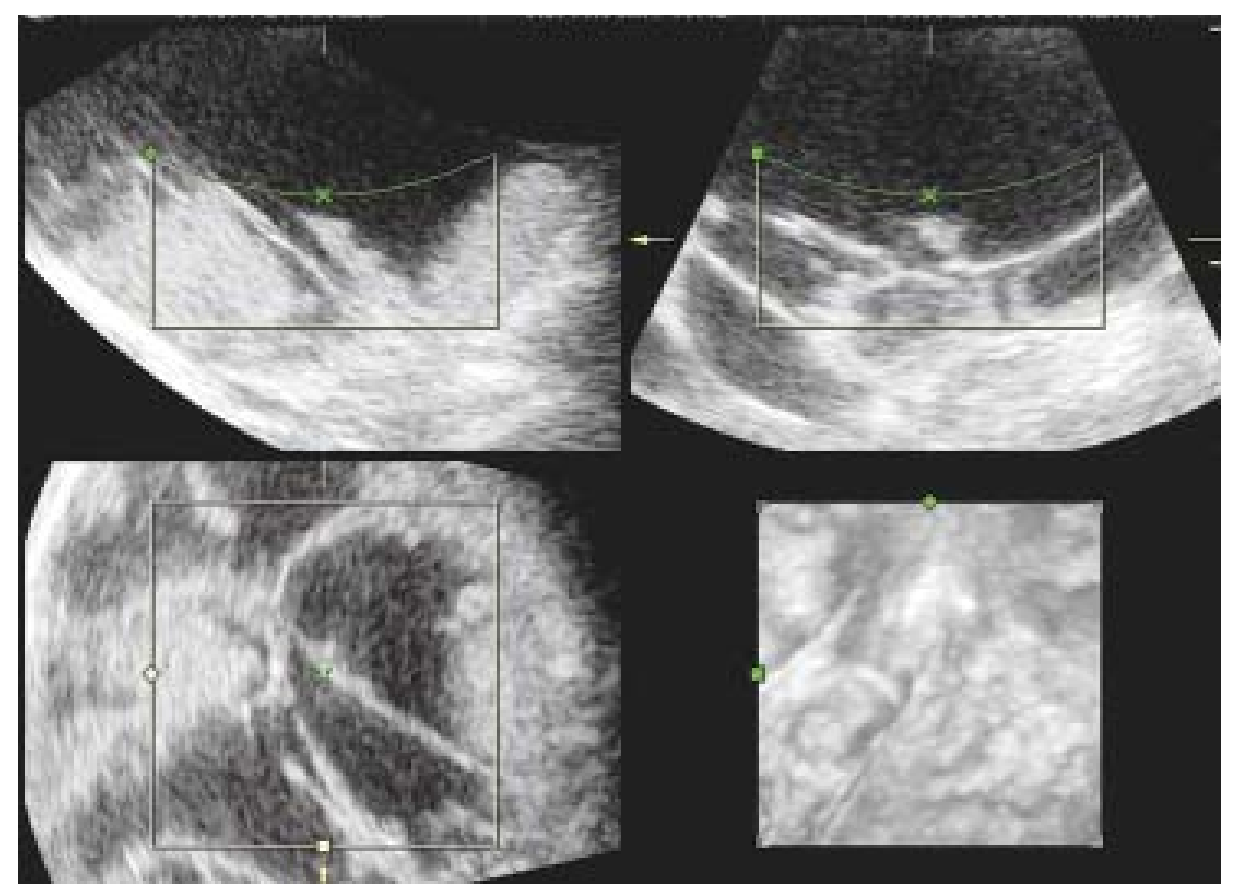

Fig. 2: Three-dimensional surface rendering from the internal wall of a complex multiloculated ovarian cyst. An irregular surface is depicted 
3D Power Doppler Ultrasonography for Discriminating Benign from Malignant Ovarian Tumors: Current Experience

Table 1: Diagnostic performance of 2D and 3D ultrasound in adnexal masses

\begin{tabular}{|c|c|c|c|c|c|}
\hline \multirow[b]{2}{*}{ Author } & \multirow[b]{2}{*}{ Ovarian cancer prevalence } & \multicolumn{2}{|c|}{ Sensitivity } & \multicolumn{2}{|c|}{ Specificity } \\
\hline & & $2 D T V S$ & $3 D$ TVS & $2 D$ TVS & $3 D$ TVS \\
\hline Bonilla-Musoles ${ }^{18}$ & $6.6 \%$ & $80 \%$ & $100 \%$ & $99 \%$ & $100 \%$ \\
\hline Hata $^{20}$ & $25 \%$ & $100 \%$ & $100 \%$ & $38 \%$ & $92 \%$ \\
\hline Kurjak $^{21}$ & $11.9 \%$ & $80 \%$ & $87 \%$ & $95 \%$ & $96 \%$ \\
\hline Alcázar $^{22}$ & $47.7 \%$ & $90 \%$ & $100 \%$ & $61 \%$ & $78 \%$ \\
\hline
\end{tabular}

Bonilla-Musoles and colleagues evaluated by twodimensional and three-dimensional ultrasonography 76 women diagnosed as having an adnexal mass. They included simple and complex masses. ${ }^{18}$ Seventy-one tumors proved to be benign and 5 malignant (cancer prevalence: 6.6\%). 2D and 3D ultrasound criteria for malignancy suspicion were the same and based on a scoring system proposed by Kurjak et al. ${ }^{19}$ They concluded that 3D US was more sensitive than 2D US (100\% versus $80 \%)$ with similar specificity (100\% and $99 \%$, respectively). These authors reported that the surface mode was able to detect some papillary projections missed on 2Dultrasound examination. It was not stated whether the same examiner or different examiners performed 2D and 3D examinations.

Hata and co-workers compared 3D US with 2D US in 20 patients with adnexal masses. ${ }^{20}$ Thirteen tumors were benign and 7 were malignant (cancer prevalence: $25 \%$ ). They included simple and complex masses. In this study one examiner performed $2 \mathrm{D}$ examination and other performed the 3D examination. Two-dimensional sonographic criteria for suspicion of malignancy were based on the scoring system proposed by Sassone et al. ${ }^{6}$ Three-dimensional ultrasound suspicion for malignancy was based on the presence of two or more of the following findings: irregular thick septa, irregular inner wall, high echogenicity and mostly solid irregular tumor. They found that 3D US was more specific than 2D US (92.3\% versus $38.4 \%$ ) being both techniques $100 \%$ sensitive.

More recently, Kurjak reported the results of a study comparing 2D and 3D ultrasound in a series of 251 adnexal tumors (221 benign tumors and 30 malignant tumors). Suspicion was based on a morphologic indexing of some features such as wall structure, septa, solid parts and echogenicity. They found 3D US more sensitive than 2D US (87\% versus $80 \%)$ with similar specificity (96\% and 95\%, respectively). ${ }^{21}$

We found that 3D ultrasonography had not statistically better diagnostic performance than 2D in a series of 44 selected complex adnexal masses. ${ }^{22}$ In our study one examiner performed 2D examination and another the 3D examination. Suspicion was based on examiner's subjective impression according to the presence of thick septations, thick papillary projections and solid areas. Differences for 3D and 2D ultrasound in terms of sensitivity (100\% versus $90 \%$ ) and specificity ( $78 \%$ versus $61 \%)$ were not statistically significant. Perhaps, this might be explained by the relatively small number of cases and by the fact that both examiners were experienced. In fact, the agreement between them was high. We found 3D US useful to reinforce initial diagnostic impression.

These controversial results might be explained by the fact that in the first two studies the number of malignant tumors was small and, probably, because all of them, except ours, included many not complex tumors. On the other hand, the sonographic criteria for malignant suspicion on 3D US were the same than in 2D US.

\section{THREE-DIMENSIONAL POWER DOPPLER ULTRASOUND}

With the advent of three-dimensional ultrasound, threedimensional power Doppler (3D-PD) imaging has become also available for clinical practice. This technique allows tumor vascularization assessment, both quantitatively-by means of 3DPD derived vascular indexes ${ }^{23}$ and qualitatively-by depicting three-dimensionally the tumor vascular network. ${ }^{24}$

Several studies have demonstrated in vivo that 3D-PD is a reliable method for assessing tumor microvasculature..$^{25-27}$

Kurjak et al, in two different studies on 120 and 90 adnexal masses, respectively, concluded that 3D-PD was superior to conventional color Doppler by increasing the sensitivity. ${ }^{24,28}$ This same group found that the use on sonographic contrast agents would improve even more the performance of 3D power Doppler $^{29}$ (Tables 2). They compared a scoring system that included some morphological features and 3D-PD evaluation of tumor vessels characteristics, such as vessels arrangement and branching pattern, with another scoring system that included the same morphological features with pulsed Doppler velocimetric parameters ( $\mathrm{RI}<0.42$ or $>0.42)$. They based their diagnostic criteria for malignancy suspicion on vessel architecture as depicted by 3D, such as branching pattern, vessel 
Table 2: Diagnostic performance of CDI and 3D-PD ultrasound in adnexal masses

\begin{tabular}{llllll}
\hline \multirow{2}{*}{ Author } & \multicolumn{2}{c}{ Sensitivity } & & \multicolumn{2}{c}{ Specificity } \\
\cline { 2 - 3 } \cline { 6 - 6 } & CDI & $3 D-P D$ & & CDI & $3 D-P D$ \\
\hline Kurjak $^{24}$ & $89 \%$ & $89 \%$ & & $95 \%$ & $97 \%$ \\
Kurjak $^{28}$ & $91 \%$ & $100 \%$ & & $97 \%$ & $99 \%$ \\
Kupesic $^{29}$ & & $100 \%$ & & $94 \%$ \\
\hline
\end{tabular}

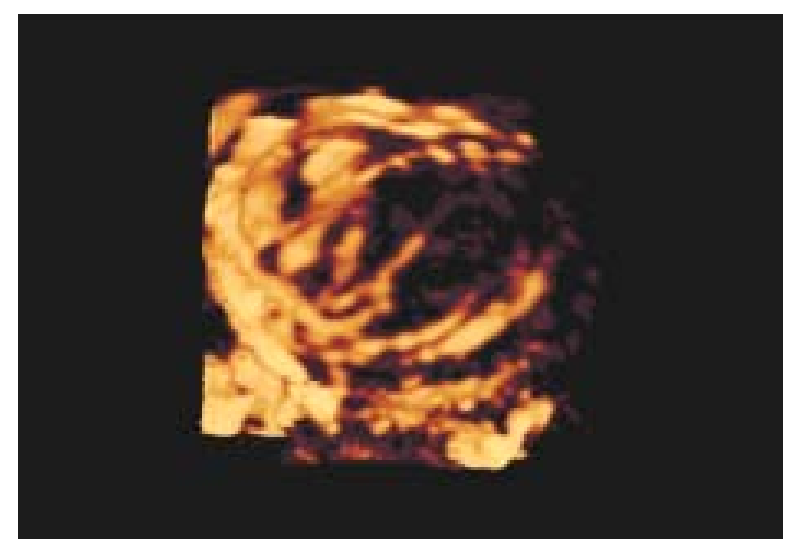

Fig. 3: Three-dimensional depiction of the vascular tree of an ovarian hemorrhagic cyst. A "nest" appearance is shown, with regular vessels caliber, and presence of microaneurysms or vascular lakes. This was based on the chaos theory, ${ }^{30}$ which establish that vascular architecture of a vascular network of newly formed vessels in malignant tumors is built following a chaotic distribution but not in a predetermined fashion (Figs 3 to 5). This has been demonstrated in corrosion studies. ${ }^{31}$

However, the reproducibility of this approach needs to be tested because it is basically based on a subjective analysis of a $3 \mathrm{D}$ reconstructed image. In fact, no study has been published addressing this issue.

Crade et al have proposed a rather similar approach, but just looking at a portion of the vascular network using the "tissue-block" technique. ${ }^{32}$ In this technique the examiner looks for focal vessel lumen changes in order to see within the arterial lumen. Conceptually, these authors propose to use stored 3D images of the vascularity to be sliced and cut away, so as to expose an optimal length of intraluminal arterial flow in the coronal plane. The examiner look specifically for "mini-jets" of flow represented as an "orange shift" of elevated mean velocity (Fig. 6). This images can only be obtained using the "magic cut" function. In their experience, the identification of “mini-jets" reported a sensitivity of $85.5 \%$ and a specificity of $90 \%$ in a series of 27 tumors (seven malignant and 20 benign).

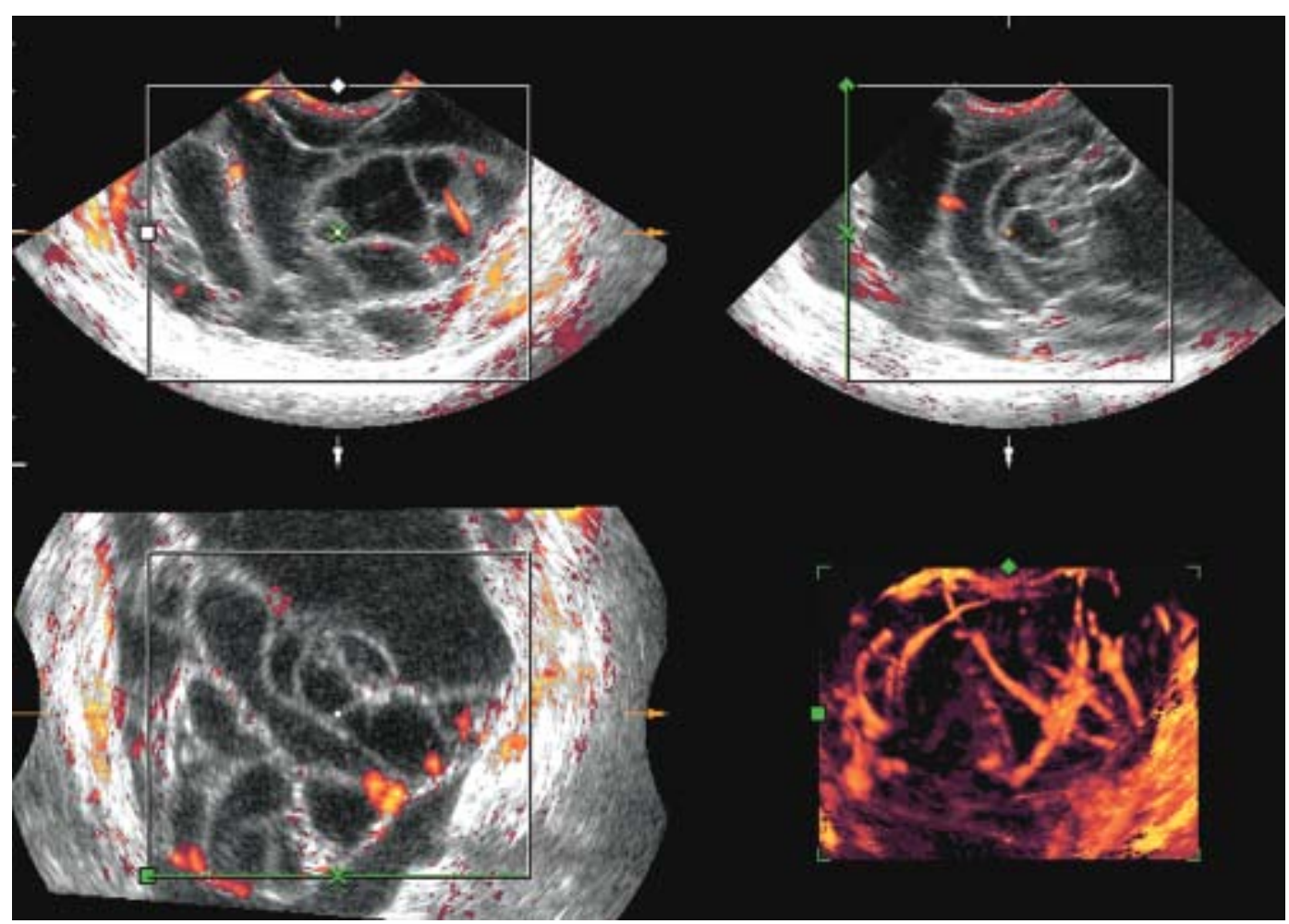

Fig. 4: Three-dimensional depiction of the vascular tree of a multiloculated cyst. It can be seen regular vessels, without abnormal branching 


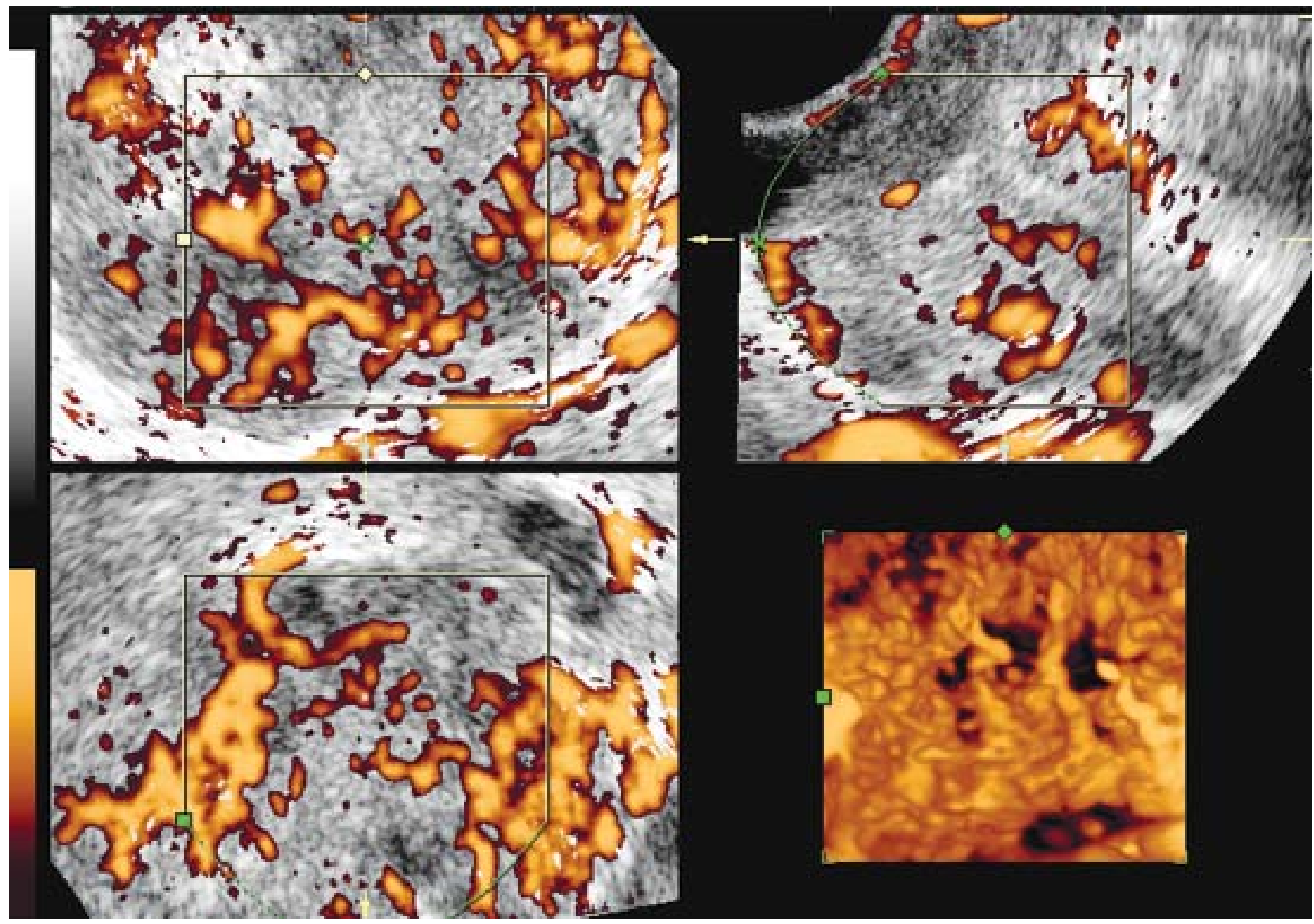

Fig. 5: Three-dimensional depiction of the vascular tree of a solid ovarian tumor. In this case an abnormal vascular network is seen, with irregular vessels, chaotic distribution and abnormal branching

Cohen et al evaluated the role of three-dimensional power Doppler in a series of 71 complex adnexal masses on 2Dtransvaginal ultrasound. ${ }^{33}$ They did not use 2D conventional color Doppler nor 2D power Doppler. In their approach, they combined 2D and 3D morphological features with 3D-PD evaluation of blood flow tumor location, considering a tumor as malignant in the presence of complex morphological pattern and central (in papillary projections and/or septations) blood flow location. They concluded that the addition of 3D-PD improved the specificity of 2D-transvaginal ultrasound (75\% versus $54 \%$ ), without decreasing the sensitivity (100\% for both techniques). These results are not surprising and can be achieved also by using a simpler technique such as color Doppler. ${ }^{34}$

We found that the diagnostic performance of 3D-PD was not statistically better than that of 2D-PD in a series of 69 complex adnexal masses, presenting both techniques similar sensitivity (97.8\% for both techniques) and specificity (87\% versus $79 \%) .{ }^{35}$ We compared the 2D-PD diagnostic criteria proposed by Guerriero et $\mathrm{al}^{34}$ with the 3D-PD diagnostic criteria proposed by Kurjak et al. ${ }^{24}$

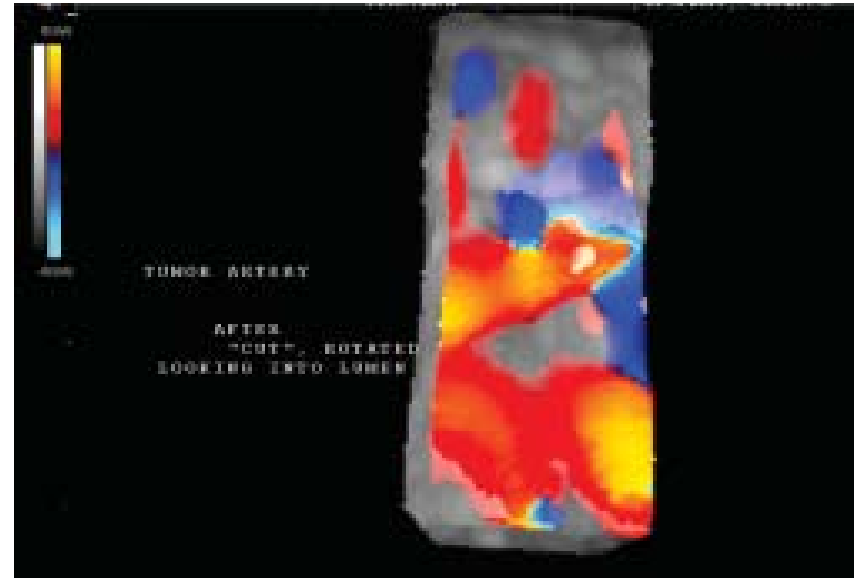

Fig. 6: The abnormal intraluminal flow pattern showing a shift in velocity, can be seen on this cut away section of the ovarian "tissue block". Note the change in velocity as indicated by the orange shifts display. Most benign masses do not have such focal shift in velocity (Courtesy: Dr Michael Crade. Irving, CA, USA) 


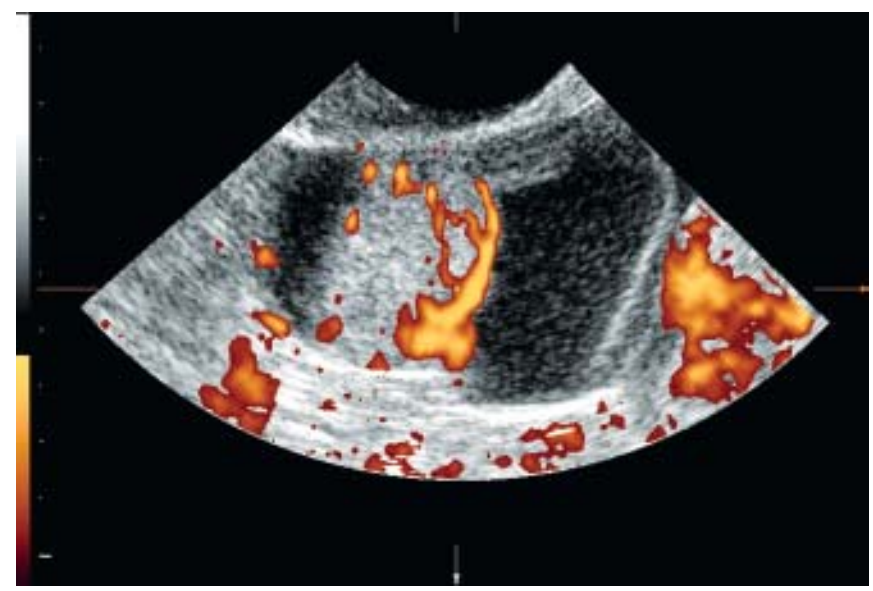

Fig. 7: Two-dimensional power Doppler image of a cystic-solid ovarian tumor, depicting a solid area with vessels within it
However, when an examiner face to a complex mass with detectable blood flow within solid areas or thick papillary projections we should categorized this mass as "malignant" or "very highly suspicious". However, a considerable number of benign tumors may exhibit this appearance, for example, cystadenofibromas, tubo-ovarian abscesses or solid benign ovarian tumors.

Using conventional 2D color or power Doppler there is no mean to differentiate these benign entities from true malignant tumors. 3D power Doppler ultrasound provides a new approach to assess tumor vascularization. We have termed this new approach “3D power Doppler vascular sampling”. ${ }^{36}$ It consists in assessing the vascularization of a given suspicious area in a given tumor by calculating 3D power Doppler derived indexes within these areas (Figs 7 to 9). In a series of 49 vascularized complex adnexal masses we found that vascularization, as

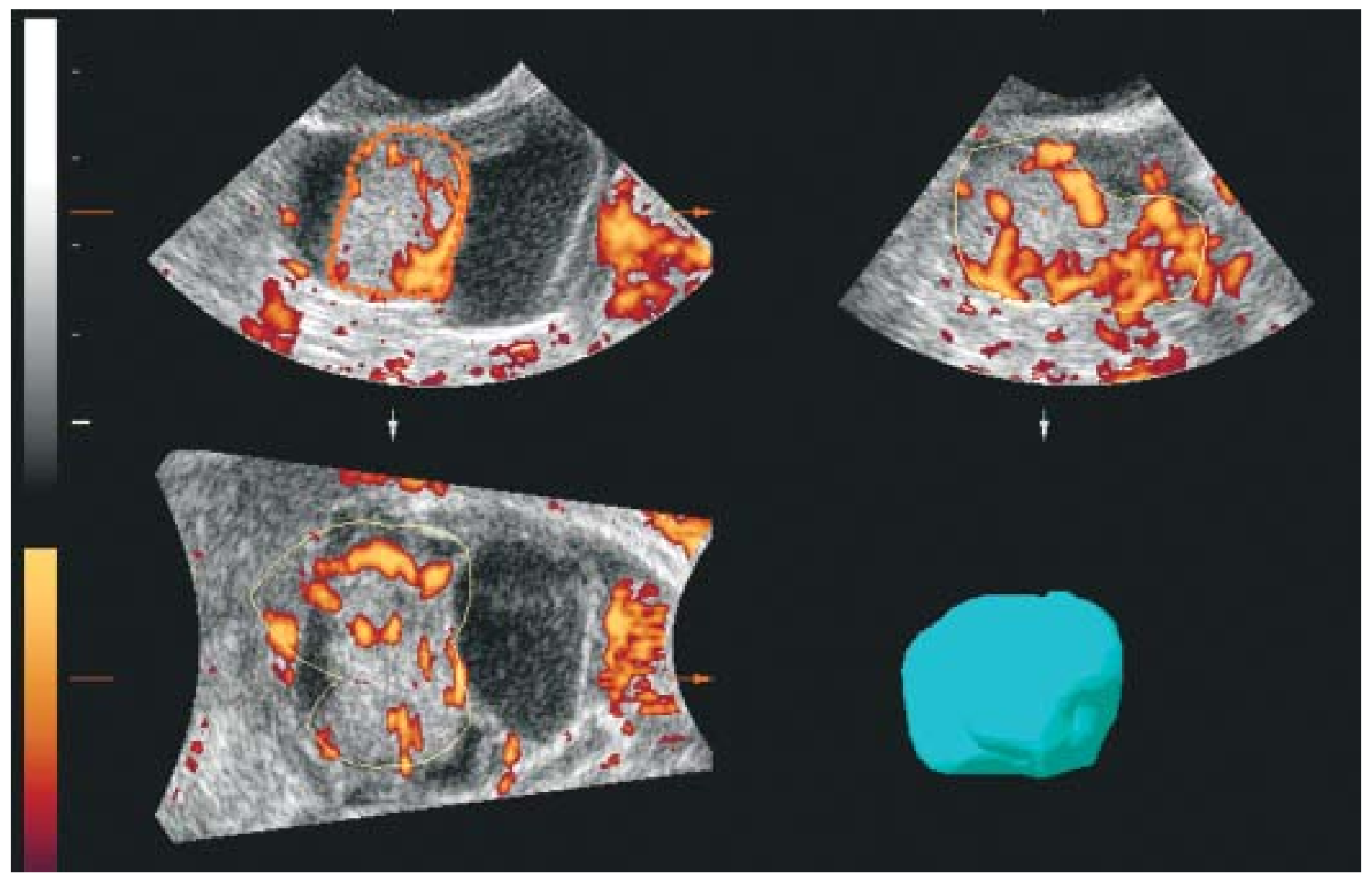

Fig. 8: Volume calculation of the solid area in the case of the previous figure by using the VOCAL software 


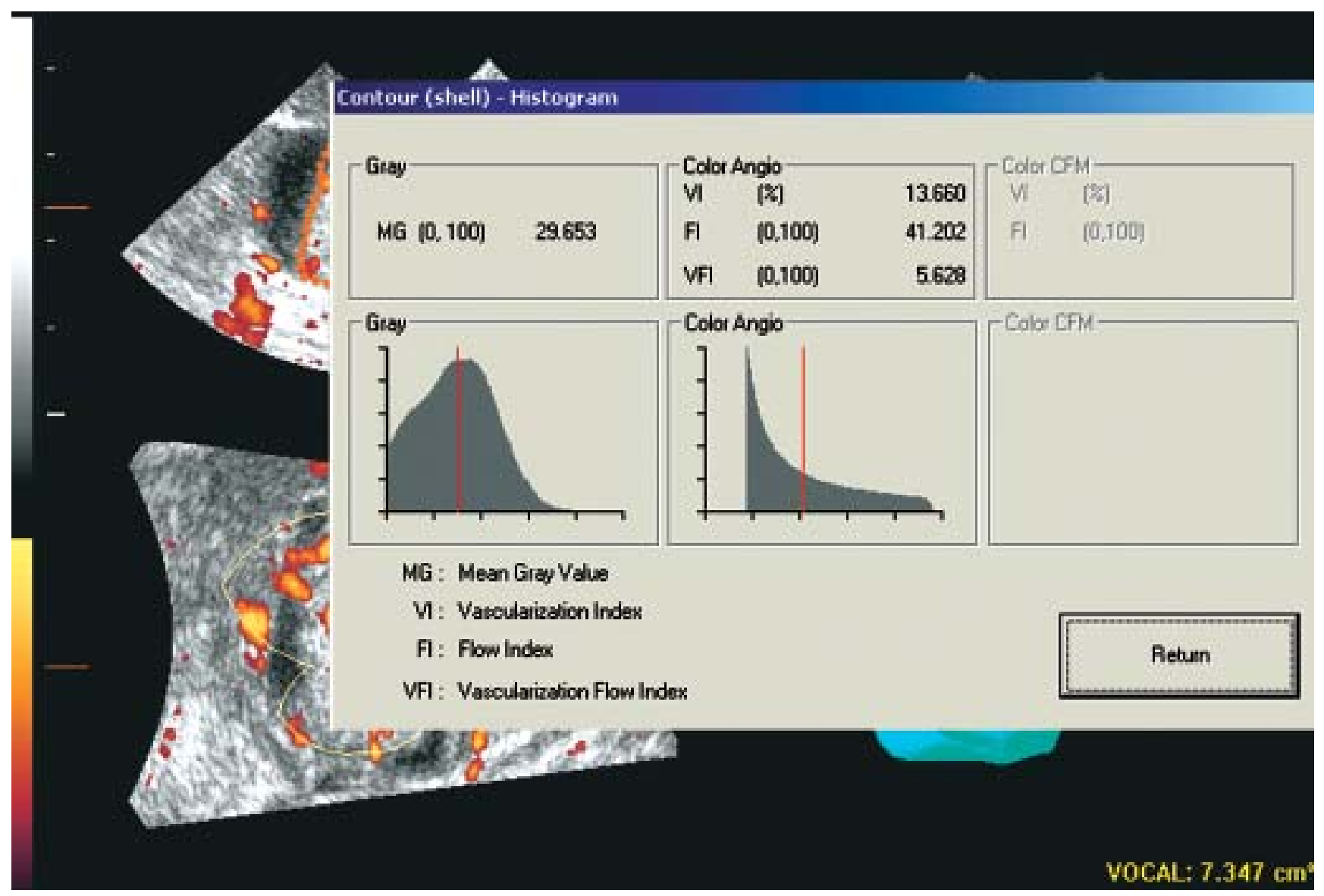

Fig. 9: Three-dimensional power Doppler indices from the solid area from

Figures 7 to 9 calculated by the VOCAL software. This is the so-called "vascular sampling"

assessed by 3D power Doppler vascular indexes were significantly higher in malignant tumors as compared with benign ones (Fig. 10). Pulsed Doppler indexes were not helpful.

Almost simultaneously to our study, Testa et al published a study on 24 solid pelvic masses with basically identical results to ours. ${ }^{37}$ Some more recent studies also report very similar results. ${ }^{38,39}$
Furthermore, we have recently demonstrated that VI and VFI indexes (Fig. 11) were higher in advanced stage and metastatic ovarian cancer than in early stage ovarian cancer. ${ }^{40}$ These preliminary results may be valuable for future research. It would be worth exploring if 3D-PD derived vascular indexes in ovarian cancer could be used as prognostic factor in ovarian cancer. 

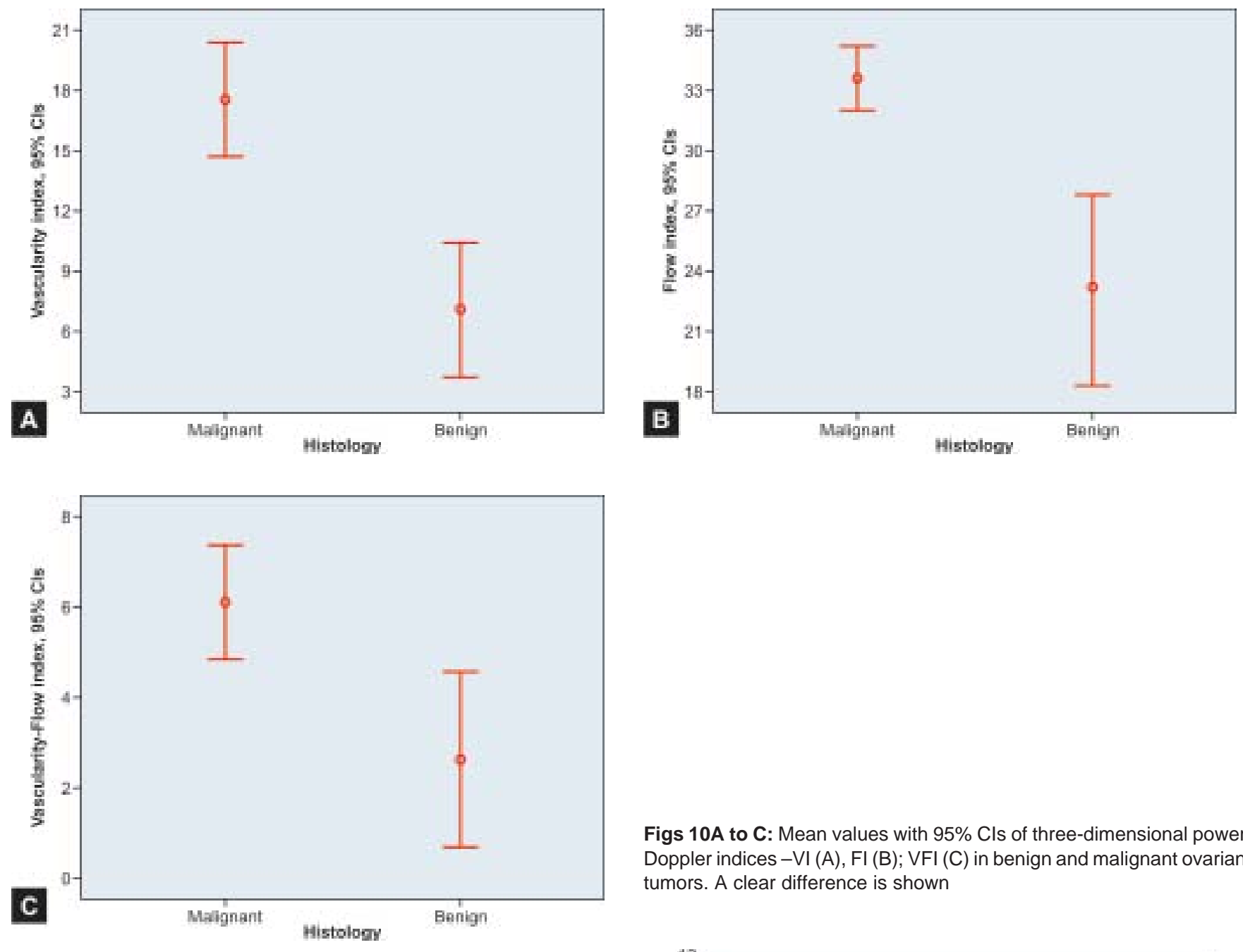

Figs $10 \mathrm{~A}$ to $\mathrm{C}$ : Mean values with $95 \% \mathrm{Cls}$ of three-dimensional power Doppler indices - VI (A), FI (B); VFI (C) in benign and malignant ovarian tumors. A clear difference is shown
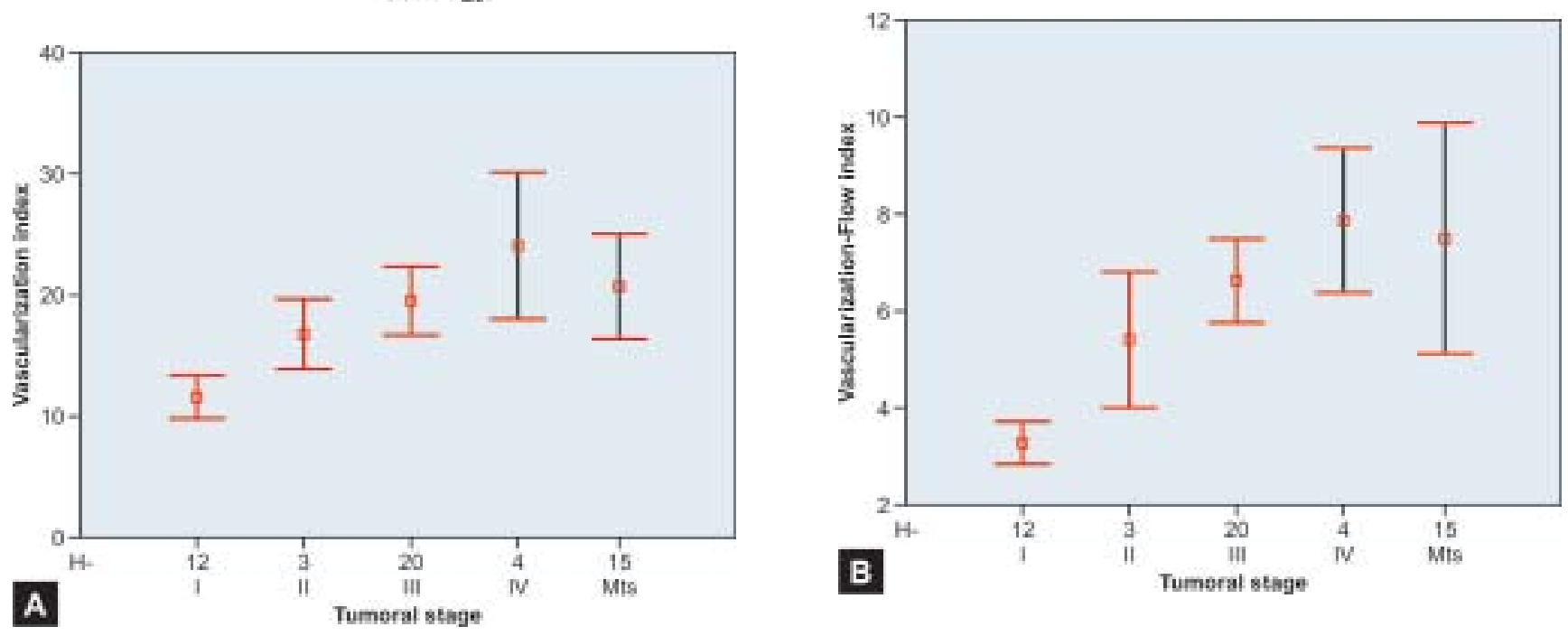

Figs 11A and B: Mean values with $95 \% \mathrm{Cls}$ of $\mathrm{VI}(\mathrm{A})$ and $\mathrm{VFI}(\mathrm{B})$ in ovarian cancer according to tumoral stage. The higher stage, the higher $\mathrm{VI}$ and $\mathrm{VFI}$ mean value 


\section{CONCLUSIONS}

Three-dimensional ultrasound should be considered still as a research tool. There are controversial data about its usefulness and specific diagnostic criteria need to be defined. The issue of reproducibility also needs to be answered.

Three-dimensional power Doppler ultrasound should be considered as a research tool, as well. There are two possible approaches: the analysis of vascular network architecture or 3D power Doppler indexes analysis of vascularized areas. There are encouraging preliminary data. The issue of reproducibility also needs to be answered.

\section{REFERENCES}

1. Farias-Eisner R, Kim YB, Berek JS. Surgical management of ovarian cancer. Semin Surg Oncol 1994;10:268-75.

2. Guerriero S, Ajossa S, Garau N, Piras B, Paoletti AM, Melis GB. Ultrasonography and color Doppler-based triage for adnexal masses to provide the most appropriate surgical approach. Am J Obstet Gynecol 2005;192:401-06.

3. Alcázar JL, Castillo G, Jurado M, López-García G. Expectant management of sonographically benign ovarian cysts in asymptomatic premenopausal women. Hum Reprod 2005;20:3231-34.

4. Alcázar JL, Errasti T, Jurado M. Blood flow in functional cysts and benign ovarian neoplasms in premenopausal women. J Ultrasound Med 1997;16: 819-24.

5. Valentin L. Pattern recognition of pelvic masses by gray scale ultrasound imaging: the contribution of Doppler ultrasound. Ultrasound Obstet Gynecol 1999;14:338-47.

6. Sassone AM, Timor-Tritsch IE, Artner A, Westhoff C, Warren WB. Transvaginal sonographic characterization of ovarian disease: Evaluation of a new scoring system to predict ovarian malignancy. Obstet Gynecol 1991;78:70-76.

7. DePriest PD, Shenson D, Fried A et al. A morphologic index based on sonographic findings in ovarian cancer. Gynecol Oncol 1993;51:7-11.

8. Ferrazzi E, Zanetta G, Dordoni D, et al. Transvaginal ultrasonographic characterization of ovarian masses: comparison of five scoring systems in a multicenter study. Ultrasound Obstet Gynecol 1997;10:192-97.

9. Alcázar JL, Mercé LT, Laparte C, Jurado M, López-García G. A new scoring system to differentiate benign from malignant adnexal masses. Am J Obstet Gynecol 2003;188:685-92.

10. Alcázar JL, Errasti T, Laparte C, Jurado M, López-García G. Assessment of a new logistic model in the preoperative evaluation of adnexal masses. J Ultrasound Med 2001;20:84148.

11. Myers ER, Bastian LA, Havrilesky LJ, et al. Management of adnexal masses. Evidence Report/Technology Assessment No 130. AHRQ Publication No 06-E004. Rockville, MD: Agency for Healthcare Research and Quality. February 2006.

12. Kurjak A, Zalud I, Alfirevic Z. Evaluation of adnexal masses with transvaginal color Doppler ultrasound. J Ultrasound Med 1991;10:295-97.
13. Alcázar JL, Ruiz-Pérez ML, Errasti T. Transvaginal color Doppler sonography in adnexal massess: which parameter performs best? Ultrasound Obstet Gynecol 1996;8:114-19.

14. Tekay A, Jouppila P. Controversies in assessment of ovarian tumors with transvaginal color Doppler ultrasound. Acta Obstet Gynecol Scand 1996;75:316-29.

15. Brown DL, Doubilet PM, Miller FM, et al. Benign and malignant ovarian masses: Selection of the most discriminating gray-scale and Doppler sonographic features. Radiology 1998;208:10310.

16. Schelling M, Braum M, Kuhn W, et al. Combined transvaginal B-mode and color Doppler sonography for differential diagnosis of ovarian tumors: results of a multivariate logistic regression analysis. Gynecol Oncol 2000;77:78-86.

17. Kinkel K, Hricak H, Lu Y, Tsuda K, Filly RA. US characterization of ovarian masses: a meta-analysis. Radiology 2000;217:803-11.

18. Bonilla-Musoles F, Raga F, Osborne NG. Three-dimensional ultrasound evaluation of ovarian masses. Gynecol Oncol 1995;59:129-35.

19. Kurjak A, Predanic M. New scoring system for predictions of ovarian malignancy based on transvaginal color Doppler sonography. J. Ultrasound Med 1992;11:631-38.

20. Hata T, Yanagihara T, Hayashi K, et al. Three-dimensional ultrasonographic evaluation of ovarian tumours: a preliminary study. Hum Reprod 1999;14:858-61.

21. Kurjak A, Kupesic S, Sparac V, Bekavac I. Preoperative evaluation of pelvic tumors by Doppler and three-dimensional sonography. J Ultrasound Med 2001;20:829-40.

22. Alcázar JL, Galán MJ, García-Manero M, Guerriero S. Threedimensional ultrasound morphologic assessment in complex adnexal masses a preliminary experience. J Ultrasound Med 2003; 22: 249-54.

23. Pairleitner H, Steiner H, Hasenoehrl G, Staudach A. Three dimensional power Doppler sonography: imaging and quantifying blood flow and vascularization. Ultrasound Obstet Gynecol 1999;14:139-43.

24. Kurjak A, Kupesic S, Sparac V, Kosuta D. Three-dimensional ultrasonographic and power Doppler characterization of ovarian lesions. Ultrasound Obstet Gynecol 2000;16:365-71.

25. Foster FS, Burns PN, Simpson DH, Wilson SR, Christopher DA, Goertz DE. Ultrasound for the visualization and quantification of tumor microcirculation. Cancer Metastasis Rev 2000;19:131-38.

26. Moskalik AP, Rubin MA, Wojno KJ, Bree R, Rubin JM, Fowlkes JB, Montie JE, Manley S, Carson PL. Analysis of threedimensional Doppler ultrasonographic quantitative measures for the discrimination of prostate cancer. J Ultrasound Med 2001;20:713-22.

27. Goertz DE, Yu JL, Kerbel RS, Burns PN, Foster FS. Highfrequency 3-D color-flow imaging of the microcirculation. Ultrasound Med Biol 2003;29:39-51.

28. Kurjak A, Kupesic S, Anic T, Kosuta D. Three-dimensional ultrasound and power Doppler improve the diagnosis of ovarian lesions. Gynecol Oncol 2000;76:28-32. 
29. Kupesic S, Kurjak A. Contrast-enhanced three-dimensional power Doppler sonography for differentiation of adnexal masses. Obstet Gynecol 2000;96:452-58.

30. Breyer B, Kurjak A. Tumor vascularization, Doppler measurements and chaos: what to do? Ultrasound Obstet Gynecol 1995;5:209-10.

31. Konerding MA, Miodonski AJ, Lametschwandtner A. Microvascular corrosion casting in the study of tumor vascularity: a review. Scanning Microsc 1995;9:1233-43.

32. Crade M, Berman M, Chase D. Three-dimensional tissue block ultrasound in ovarian tumors. Ultrasound Obstet Gynecol 2005;26:683-86.

33. Cohen LS, Escobar PF, Scharm C, Glimco B, Fishman DA. Three-dimensional ultrasound power Doppler improves the diagnostic accuracy for ovarian cancer prediction. Gynecol Oncol 2001;82:40-48.

34. Guerriero S, Alcázar JL, Coccia ME, Ajossa S, Scarselli G, Boi $\mathrm{M}$, et al. Complex pelvic mass as a target of evaluation of vessel distribution by color Doppler for the diagnosis of adnexal malignancies: results of a multicenter European study. J Ultrasound Med 2002;21:1105-11.

35. Alcázar JL, Castillo G. Comparison of 2-dimensional and 3D power Doppler imaging in complex adnexal masses for the prediction of ovarian cancer. Am J Obstet Gynecol 2005;192:807-12.

36. Alcazar JL, Merce LT, Garcia Manero M. Three-dimensional power Doppler vascular sampling: a new method for predicting ovarian cancer in vascularized complex adnexal masses. J Ultrasound Med 2005;24:689-96.

37. Testa AC, Ajossa S, Ferrandina G, et al. Does quantitative analysis of three-dimensional power Doppler angiography have a role in the diagnosis of malignant pelvic solid tumors? A preliminary study. Ultrasound Obstet Gynecol 2005;26:67-72.

38. Czekierdowski A, Smolen A, Danilos J, Kotarski J. Application of three-dimensional ultrasound "vascular tumor biopsy” for the discrimination of ovarian tumors. Ultrasound Obstet Gynecol 2006;28 (supl 1): 404.

39. Romanini ME, Exacoustos C, Amadio A, Amoroso A, Szabolcs B, Zupi A, Arduini D. Adnexal cysts with papillae: role of threedimensional power Doppler ultrasound for discrimination between benign, borderline and invasive malignant ovarian tumors. Ultrasound Obstet Gynecol 2006; 28 (supl 1):510.

40. Alcázar JL. Tumor angiogenesis assessed by three-dimensional power Doppler ultrasound in early, advanced and metastatic ovarian cancer: a preliminary study. Ultrasound Obstet Gynecol 2006;28:325-29. 